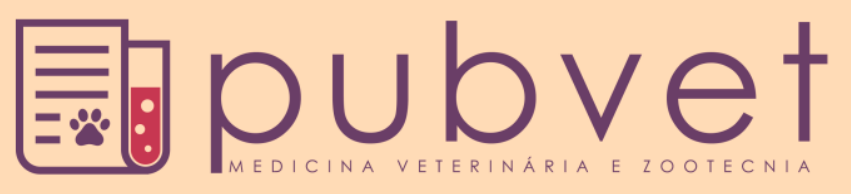

HTTP://DX.DOI.ORG/10.22256/PUBVET.V11N11.1129-1131

\title{
Frequência de cães geriátricos positivos ao teste de ácido úrico
}

\author{
Paulo Henrique Braz ${ }^{1}$, Taís Ramires da Silva², Nayara Quevedo do Nascimento ${ }^{3}$
}

${ }^{1}$ Docente do Centro Universitário da Grande Dourados, Departamento de Patologia Clínica Veterinária. Dourados -MS Brasil.E-mail:pauloh.braz@hotmail.com

${ }^{2}$ Discente do Centro Universitário da Grande Dourados, Departamento de Patologia Clínica Veterinária. Dourados -MS Brasil.E-mail: taisramires.silva@hotmail.com

${ }^{3}$ Discente do Centro Universitário da Grande Dourados, Departamento de Patologia Clínica Veterinária. Dourados - MS Brasil. E-mail: nayaraquevedo@hotmail.com

RESUMO. Este trabalho teve como objetivo avaliar a frequência de testes positivos de ácido úrico realizados em animais geriátricos e sua relação com a causa e o diagnóstico de doenças causadas por alterações deste fator. Foram utilizados 15 cães sem raça definida. Dentre os animais submetidos aos testes, nenhum apresentou alteração nos níveis de ácido úrico. Pode ser concluído que os testes positivos de ácido úrico têm baixa frequência quando realizados em animais geriátricos.

Palavras chave: Artrite, imunomediada, geriatria

\section{Frequency of geriatric animals positive for uric acid test}

ABSTRACT. The objective of this study was to evaluate the frequency of positive uric acid tests performed on geriatric animals and their relationship to the cause and diagnosis of diseases caused by changes in this factor. 15 dogs with no defined gender and race were used. Among the animals submitted to the tests, none showed alterations in uric acid levels and only one was positive for rheumatoid factor. It can be concluded that positive tests of rheumatoid factor and uric acid have low frequency when performed in geriatric animals.

Key words: Arthritis, immune-mediated, geriatrics

\section{Frecuencia de animales geriátricos positivos a la prueba de ácido úrico}

RESUMEN. Este trabajo tuvo como objetivo evaluar la frecuencia de pruebas positivas de ácido úrico realizadas en animales geriátricos y su relación con la causa y el diagnóstico de enfermedades causadas por alteraciones de este factor. Se utilizaron 15 perros sin raza definida. Entre los animales sometidos a las pruebas, ninguno presentó alteración en los niveles de ácido úrico. Se puede concluir que las pruebas positivas de ácido úrico tienen baja frecuencia cuando se realizan en animales geriátricos.

Palabras clave: Artritis, inmunodeficiencia, geriatría

\section{Introdução}

Nos animais, o metabolismo das bases purínicas é responsável pela formação do ácido úrico, onde a guanina e adenina são convertidas em xantina e hipoxantina, sofrendo posteriormente ação da xantina oxidase (Lima et al., 2008).
O ácido úrico é conhecido como um ácido fraco e sua quantidade no organismo depende do equilíbrio entre a ingestão na dieta, a taxa de excreção e a síntese endógena. Sendo assim, o aumento nos níveis de ácido úrico pode ser consequência da diminuição da excreção ou do aumento da sua produção (Pinheiro, 2008). 
Uma das alterações que ocorre durante a eliminação do ácido úrico resulta em acúmulo de uratos e cristalização do ácido nas articulações, resultando em gota articular (Pinheiro, 2008). A doença pode se apresentar em 3 fases distintas. A fase assintomática, a fase aguda, que intercala entre intervalos assintomáticos e com sinais de inflamação, e as crises agudas, que geram limitação nos movimentos. Os pacientes idosos são os que apresentam os sintomas com maior frequência (Farias et al., 2010).

O objetivo deste trabalho foi avaliar a frequência com que os cães geriátricos atendidos em um hospital escola se apresentam positivos quando submetidos ao teste de ácido úrico, considerando que as alterações deste fator são responsáveis por ocasionar doenças que acometem animais com idade mais avançada, assim como usar desses resultados para o diagnóstico e tratamento desses animais.

\section{Material e Métodos}

Neste estudo foram utilizados 15 cães saudáveis de diversas raças e ambos os sexos, com idade superior a 8 anos, com peso variando entre 10 e $15 \mathrm{~kg}$, provenientes da rotina clínica do hospital veterinário do Centro Universitário da Grande Dourados.

Os animais inclusos no projeto foram levados ao atendimento clínico para check-up de rotina. Foram submetidos a colheita de sangue por punção venosa e o sangue foi acondicionado em um tubo sem anticoagulante. Após coagulação sanguínea foi realizada centrifugação da amostra e extraído o soro para realização do teste de ácido úrico.

Para a dosagem de ácido úrico foram utilizados $20 \mu \mathrm{L}$ de soro diluído em $1000 \mu \mathrm{L}$ de reagente químico (Gold Analisa ${ }^{\circledR}$ ). A amostra foi incubada em banho maria a $37^{\circ} \mathrm{C}$ por 5 minutos e a amostra colocada para leitura em espectrofotômetro semiautomático.

\section{Resultados e Discussão}

A utilização da mensuração de níveis séricos de ácido úrico se deve predominantemente para o diagnóstico de uma desordem clínica conhecida como gota, na qual a hiperuricemia é um fator de risco para tal doença e que ocorre devido à deposição de cristais de uratos monossódicos insolúveis nas articulações. Além dos distúrbios relacionados às articulações, há outros fatores que elevam a atividade sérica de ácido úrico no organismo, como as doenças cardiovasculares, obesidade, dislipidemia, hipertensão arterial e, mais recentemente, à síndrome metabólica (Coutinho et al., 2007, Gagliardi et al., 2009), doenças rotineiramente encontradas em cães geriátricos.

Na medicina veterinária há poucos relatos de mensuração do ácido úrico para acompanhamento de doenças, principalmente em cães geriátricos, propensos a diversas doenças senis. A proposta de determinar um perfil bioquímico sérico do ácido úrico se deve por considera-lo um marcador de prognóstico para o desenvolvimento de doenças vasculares e doença renal (Iseki et al., 2004). Dentre os 15 cães geriátricos acompanhados na rotina clínica, todos obtiveram resultado sérico igual a zero.

Outros fatores que geram aumento da concentração de ácido úrico no organismo são as síndromes metabólicas. Estão inclusas neste patamar a intolerância à glicose, resistência à insulina, obesidade abdominal, dislipidemia aterogênica e hipertensão, sendo todos os fatores de risco documentados para doença arterial coronariana. Em seres humanos já existe determinação de que há estreita conexão entre elevadas concentrações de ácido úrico sérico e o aumento da prevalência de síndrome metabólica (Yoo et al., 2005). Estes fatos permitem inferir que os níveis séricos de ácido úrico poderiam também ser incluídos na definição de síndrome metabólica.

As resistências à insulina e hiperinsulinemia levam à elevação do ácido úrico sérico por mecanismos diretos e indiretos, que incluem o aumento da produção de urato, assim como a excreção renal de urato diminuída. Os níveis elevados de ácido úrico também podem agravar a resistência insulínica e outros processos associados, como a hipertensão, intolerância à glicose, dislipidemia aterogênica, e a disfunção endotelial, aumentando assim o risco cardiovascular (Marion et al., 2011).

\section{Conclusão}

Como foi demonstrado nos resultados obtidos, cães idosos livres de doenças primárias mantêm o nível de ácido úrico baixo, desta forma, há necessidade de estudos referentes a doenças que afetem o sistema cardiorrenal e metabólico para averiguação do determinante prognóstico que o exame de ácido úrico pode sugerir. 


\section{Referências Bibliográficas}

Coutinho, T. A., Turner, S. T., Peyser, P. A., Bielak, L. F., Sheedy, P. F. \& Kullo, I. J. 2007. Associations of serum uric acid with markers of inflammation, metabolic syndrome, and subclinical coronary atherosclerosis. American Journal of Hypertension, 20, 83-89.

Farias, R. J. M., Venancio, R. A. \& Camparis, C. M. 2010. Alterações sistêmicas e suas relações com dores orofaciais. Jornal Brasileiro de Oclusão, 2, 121-126.

Gagliardi, A. C. M., Miname, M. H. \& Santos, R. D. 2009. Uric acid: a marker of increased cardiovascular risk. Atherosclerosis, 202, 1117.

Iseki, K., Ikemiya, Y., Inoue, T., Iseki, C., Kinjo, K. \& Takishita, S. 2004. Significance of hyperuricemia as a risk factor for developing ESRD in a screened cohort. American Journal of Kidney Diseases, 44, 642-650.

Lima, L. R. P., Oliveira, T. T., Nagem, T. J., Pinto, A. S., Tinoco, A. L. A., Silva, J. F. \& Oliveira, M. L. 2008. Ação terapêutica e inocuidade no metabolismo de quercetina, bixina e norbixina em coelhos hiperlipidêmicos. Revista de Tecnologia e Ciências Agropecuária, 2, 51-56.

Marion, M., Carvalho, J. A. M., Bochi, G. V., Sangoi, M. B. \& Moresco, R. N. 2011. Ácido úrico como fator de risco para doenças cardiovasculares e síndrome metabólica. Revista Brasileira de Farmácia, 92, 3-8.

Pinheiro, G. R. C. 2008. Revendo a orientação dietética na gota. Revista Brasileira de Reumatologia, 8, 157-161.

Yoo, T. W., Sung, K. C., Shin, H. S., Kim, B. J., Kim, B. S., Kang, J. H., Lee, M. H., Park, J. R., Kim, H. \& Rhee, E. J. 2005. Relationship between serum uric acid concentration and insulin resistance and metabolic syndrome. Circulation Journal, 69, 928-933.

Article History:

Received 10 June 2017

Accepted 31 August 2017

Available on line 8 September 2017

License information: This is an open-access article distributed under the terms of the Creative Commons Attribution License 4.0, which permits unrestricted use, distribution, and reproduction in any medium, provided the original work is properly cited. 